Re-submitted to: Chemosphere (CHEM19045R1)

Date: $\quad$ September 15, 2010

\title{
Biodegradation and Biotransformation of Wastewater Organics as Precursors of Disinfection Byproducts in Water
}

\author{
Jin-lin Liu and Xiao-yan Li* \\ Environmental Engineering Research Centre, Department of Civil Engineering, \\ The University of Hong Kong, Pokfulam Road, Hong Kong, China
}

*Corresponding Author:
Phone:
(852) 2859-2659
Fax:
(852) 2559-5337
Email:
xlia@hkucc.hku.hk
Homepage: http://web.hku.hk/ xlia/ 


\section{Abstract}

Laboratory experiments were carried out to investigate wastewater organics as the precursors of disinfection byproducts (DBPs) in drinking water supply. The focus was on the change in wastewater DBP precursors during biological degradation under simulated natural conditions. The wastewater and its treated secondary effluent were characterized for DBP formation potential (DBPFP) and DBP speciation profile, including trihalomethanes, haloacetic acids, chloral hydrate, and nitrogen-containing DBPs. Several model organic compounds, including humic acid, tannic acid, glucose, starch, glycine, and bovine serum albumin (BSA), were used to represent the different types of organic pollutants in wastewater

Keywords: Biodegradation; disinfection byproducts (DBPs); DBP precursors; drinking water 


\section{Introduction}

Organic matter in the raw water supply is the primary precursor of disinfection byproducts (DBPs) in finished drinking water. The main organic DBP groups of concern include trihalomethanes (THMs) and haloacetic acids (HAAs) (Singer, 1999; Xie, 2004). It has been found that THMs, some HAA species such as dichloroacetic acid (DCAA), and other chlorinated DBPs are carcinogenic, mutagenic, and teratogenic (Bull, 1993; Koivusalo et al., 1997; Waller et al., 1998; Xie, 2004). Natural organic matter (NOM) is the major reservoir of organic DBP precursors in surface water (Singer, 1999; Chang et al., 2001; Hua and Reckhow, 2007). Numerous studies have been conducted on the characteristics, reactivity, and DBP yield of NOM following water chlorination (Singer, 1999; Xie, 2004).

Due to the worldwide decline of water resources, treated wastewater now represents a growing portion of the water supply. Many surface water bodies, such as rivers, lakes, and reservoirs, are used for both the disposal of treated wastewater and the withdrawal of fresh water for human consumption. The regulations for wastewater disposal were generally developed to protect the quality of the receiving waters and people using such waters for recreational purposes. However, there is limited information about the DBP precursors arising from wastewater discharge. Organic matter in wastewater effluent is likely to contribute to the DBP precursors of the receiving water, resulting in greater DBP formation in drinking water (Galapate et al., 1997; Galapate et al., 1999; Rostad et al., 2000; Chu et al., 2002; Krasner et al., 2009a; Krasner et al., 2009b). Hence, to ensure the safety of the drinking water supply, the problem of wastewater-derived DBP formation needs to be specifically addressed. Moreover, discharged wastewater organics undergo further biodegradation in the 
receiving water under natural conditions. During the biotransformation process, wastewater organics are expected to change in terms of their reactivity with chlorine and their DBP formation characteristics (Chang et al., 2001; Chen et al., 2009). In this experimental study, wastewater organics were characterized for their DBP formation potential (DBPFP) and the resulting DBP speciation in chlorinated water. The process of biological organic degradation was conducted under laboratory conditions, and several model organics, including carbohydrates, proteins, humic acid, tannic acid, and glycine, were used to simulate organic pollutants. The aims of the study were to determine the DBPFP of different types of organic substances in wastewater and the resulting DBP species, and to investigate the changes in the DBP formation behavior of different wastewater organics during the biodegradation process.

\section{Materials and Methods}

60

\subsection{Wastewater samples}

Wastewater samples of raw sewage and secondary effluent were collected from a full-scale municipal biological sewage treatment plant (Stanley Sewage Treatment Works, Hong Kong). The activated sludge process was adopted in the treatment system, which had a sludge age of around $15 \mathrm{~d}$ and produced an effluent with a BOD of around $5 \mathrm{mg} \mathrm{L}^{-1}$ and a suspended solids (SS) concentration of about $5 \mathrm{mg} \mathrm{L}^{-1}$. The raw sewage influent had a BOD of $130 \mathrm{mg} \mathrm{L}^{-1}$, an SS of about $70 \mathrm{mg} \mathrm{L}^{-1}$, a dissolved organic carbon (DOC) of $40 \mathrm{mg} \mathrm{L}^{-1}$, and a UV absorbance at $254 \mathrm{~nm}\left(\mathrm{UV}_{254}\right)$ of $0.201 \mathrm{~cm}^{-1}$. The secondary effluent had a DOC of 14 $\mathrm{mg} \mathrm{L}^{-1}$ and a $\mathrm{UV}_{254}$ of $0.077 \mathrm{~cm}^{-1}$. The wastewater samples were filtered immediately after 
collection through $0.45 \mu \mathrm{m}$ filter paper to remove any suspended matter, and the filtrates were stored in a refrigerator at $4{ }^{\circ} \mathrm{C}$ for later experimental use.

\subsection{Model wastewater organic compounds}

Six types of model organic chemicals were chosen to simulate the typical organic components found in municipal wastewater. They included humic acid (product no. 2S101H, IHSS Suwannee River Standard, St. Paul, MN, USA), tannic acid (Sigma, St. Louis, NC, USA), glucose (Unichem, Haw River, MO, USA), starch (Riedel-de Haen, Seelze, Hanover, Germany), glycine (BDH, Yorkshire, UK), and bovine serum albumin (BSA) (USB, Cleveland, $\mathrm{OH}$, USA). Humic acid usually results from organic degradation and plant mineralization, and tannic acid is one of the humic precursors in organic degradation. Both types of chemical substances have been found at various levels in wastewater (Dignac et al., 2000). Carbohydrates and proteins are believed to be the two predominant organic groups in wastewater (Dignac et al., 2000; Dignac et al., 2001). In this study, glucose and starch were used to represent the carbohydrate group. Glucose is the simplest carbohydrate molecule, and starch is a polymeric carbohydrate with the molecular structure $\left(\mathrm{C}_{6} \mathrm{H}_{10} \mathrm{O}_{5}\right)_{\mathrm{n}}$. BSA is a typical protein used in numerous commercial products, and the amino acid glycine $\left(\mathrm{NH}_{2}-\mathrm{CH}_{2}-\mathrm{COOH}\right)$ is one of the simplest protein degradation products. Each model organic was dissolved in water to make a synthetic wastewater solution sample for the DBP study. The water used for making the organic solutions was ultrapure water produced by the Milli-Q water purification system (Millipore, Billerica, MA, USA). The initial DOC concentrations of the humic acid and tannic acid solutions were set at 3 and $10 \mathrm{mg} \mathrm{L}^{-1}$, respectively, and the 
initial DOC concentrations of the other four organic solutions were all $80 \mathrm{mg} \mathrm{L}^{-1}$.

\subsection{Organic degradation experiment}

The natural degradation of the wastewater organics and the model organic compounds was simulated in a temperature-controlled incubator at $20^{\circ} \mathrm{C}$. The setup and approach of the biodegradation experiment were similar to those used for the conventional BOD test. The biodegradation of the sample solutions was carried out in a batch reactor with an initial water volume of $5 \mathrm{~L}$ and placed in a BOD incubator (Velp Scientifica, Usmate, Italy). N, P and trace nutrients were added to the model organic solutions according to the guidelines given solids before the subsequent DBP formation potential tests.

\subsection{Determination of the DBPFP}

The DBPFP of the wastewater organics was measured for the water samples after different periods of biodegradation. DBP formation tests were carried out on the filtered 
water samples upon chlorine disinfection in accordance with the Standard Methods (APHA, 1998). For each DBPFP test, a $100 \mathrm{~mL}$ water sample was chlorinated with $\mathrm{NaOCl}$, and the resulting solution incubated for $7 \mathrm{~d}$ at $\mathrm{pH} 7.0 \pm 0.2$ with a $0.5 \mathrm{M}$ phosphate buffer. The dose of 

Methyl tert-butyl ether (MTBE) was used as the solvent for liquid extraction, and the chemicals extracted in the solvent were analyzed by the GC. One $\mu \mathrm{L}$ of the extract solution was introduced into the GC by splitless injection at $200{ }^{\circ} \mathrm{C}$. The carrier gas was $\mathrm{N}_{2}$, which was delivered at a constant flow-rate of $0.8 \mathrm{~mL} \mathrm{~min}^{-1}$. The initial oven temperature was set at $35^{\circ} \mathrm{C}$ and held for $9 \mathrm{~min}$. The temperature was gradually increased first to $40{ }^{\circ} \mathrm{C}$ at a rate of 2 ${ }^{\circ} \mathrm{C} \min ^{-1}$, then to $80{ }^{\circ} \mathrm{C}$ at $20^{\circ} \mathrm{C} \min ^{-1}$, then to $160{ }^{\circ} \mathrm{C}$ at a rate of $40{ }^{\circ} \mathrm{C} \min ^{-1}$, held for $4 \mathrm{~min}$, and finally to $200^{\circ} \mathrm{C}$, held for $2 \mathrm{~min}$. The detector temperature was set at $290{ }^{\circ} \mathrm{C}$ for detection of the four THM compounds, trihaloacetaldehydes, halopropanones, and haloacetonitriles and trihalonitromethanes.

The method used to analyze the HAA compounds was developed based on EPA Method 552.3 (USEPA, 2003) with some modifications by others (Xie et al., 2002; Domino et al., 2004). In brief, the HAAs in the water samples were extracted with MTBE. Derivatization was then performed on the extract by adding acidic methanol at a 1:1 (v/v) ratio. One $\mu \mathrm{L}$ of the sample was introduced into the GC by splitless injection at $200{ }^{\circ} \mathrm{C}$. The carrier $\mathrm{N}_{2}$ gas was maintained at a flow-rate of $0.9 \mathrm{~mL} \mathrm{~min}{ }^{-1}$. The temperature program began at $35{ }^{\circ} \mathrm{C}$ for 10 min and increased at a rate of $5{ }^{\circ} \mathrm{C} \min ^{-1}$ to $70{ }^{\circ} \mathrm{C}$, where it was held for $10 \mathrm{~min}$, then to 120 ${ }^{\circ} \mathrm{C}$ for $5 \mathrm{~min}$, then to $135^{\circ} \mathrm{C}$ for $10 \mathrm{~min}$, and finally to $170{ }^{\circ} \mathrm{C}$, where it was held for $5 \mathrm{~min}$. The detector temperature was $260{ }^{\circ} \mathrm{C}$ for the HAA detection.

\subsection{Analytical methods}

The SS concentration for the biomass content in a bioreactor during the wastewater 
biodegradation process was measured in accordance with the Standard Methods (APHA, 1998). The $U_{254}$ and DOC of the organic content were measured for each water sample after filtration. $\mathrm{UV}_{254}$ has been used as an index of aromatic structures, which are closely related to Loveland, CO, USA) using the catalytic combustion-infrared method.

\section{Results and Discussion}

\subsection{Initial DBP formation characteristics of the wastewater and model organic compounds}

Seven DBP species were detected at a significant level in the water samples tested, including $\mathrm{CF}$ for the THMs, DCAA and TCAA for the HAAs, $\mathrm{CH}$ for the trihaloacetaldehydes, TCP for the halopropanones, DCAN for the haloacetonitriles, and TCNM for the trihalonitromethanes. The last two are both N-DBPs. According to the DBPFP test, the raw wastewater and its secondary effluent and the six model organics - humic acid, tannic acid, glucose, starch, glycine, and BSA - had rather different DBPFP values upon chlorination in terms of the DBPFP yield per unit amount of DOC (Fig. 1a). Humic acid had the highest DBPFP yield at $493 \mu \mathrm{g} \mathrm{mg}^{-1}$ DOC, suggesting a strong DBP formation reactivity with chlorine. The DBPFP yields of tannic acid (365 $\mu \mathrm{g} \mathrm{mg}^{-1}$ DOC) and BSA (193 $\mu \mathrm{g} \mathrm{mg}^{-1}$ DOC) were comparably lower. The other three model organics - glucose, starch, and glycine - had much lower DBPFP yields with values of 1,1 , and $3 \mu \mathrm{g} \mathrm{mg}^{-1}$ DOC, respectively. 
The organic matter in the actual wastewater had a DBPFP yield that was significantly lower than that of humic acid, tannic acid, and BSA but much higher than that of glucose, starch, and glycine. In comparison, the DBPFP yield of the organic in the treated wastewater 


\subsubsection{Wastewater influent and effluent}

Various changes in organic content and related DBPFP values were observed after $10 \mathrm{~d}$ of biodegradation for the actual wastewater samples and most of the model organic solutions (Figs. 2-5). The actual wastewater influent had an initial DOC concentration of $40 \mathrm{mg} \mathrm{L}^{-1}$ and 

at the beginning of the biodegradation incubation (Fig. 2b). Compared to the wastewater influent, the organic in the secondary effluent was much more refractory to biodegradation.

\subsubsection{Humic acid and tannic acid}

Humic acid is the main component of NOM that is not considered to be biodegradable. As expected, the humic acid content remained largely constant throughout the biodegradation process in terms of DOC concentration, $\mathrm{UV}_{254}$ absorbance, and DBPFP (Fig. 3). The humic acid solution with a DOC of $3 \mathrm{mg} \mathrm{L}^{-1}$ had a high DBPFP of $1428 \mu \mathrm{g} \mathrm{L} \mathrm{L}^{-1}$. The large DBPFP yield of humic acid is attributed to its abundant aromatic rings, which have been identified as a major DBP-forming molecular structure (Arora et al., 1997; Liang and Singer, 2003; Archer 
and Singer, 2006). Humic acid gave rise to the formation of all seven DBP species detected in this study. The DBPFP speciation was dominated by THMs (CF), followed by HAAs (TCAA

\subsubsection{Glucose and starch}

Carbohydrates are believed to be the major components of wastewater organics (Dignac et al., 2000). Both of the model carbohydrate organics - glucose and starch - were readily degraded by microorganisms. The DOC of the organic solutions decreased rapidly from a 

thereafter (Fig. 4). However, the $\mathrm{UV}_{254}$ of the model organic solutions increased during the biodegradation process. The $\mathrm{UV}_{254}$ increase suggests a possible biological transformation of 
$\mathrm{mg}^{-1}$ DOC for the glucose and starch solutions, respectively (Fig. 4).

Pure glucose resulted in the formation of only THM (CF), whereas starch produced mainly CF and trace amounts of $\mathrm{CH}$ and HAAs (DCAA and TCAA). During biodegradation,

\subsubsection{Glycine and BSA}

Both glycine and BSA are biodegradable N-containing organics. BSA was rapidly

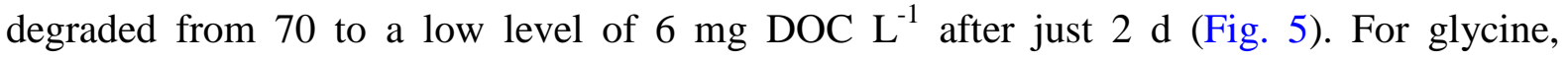
biodegradation began to take place after $2 \mathrm{~d}$ and was completed rapidly in the following $2 \mathrm{~d}$. During the degradation process, $\mathrm{UV}_{254}$ decreased for the BSA solution and increased somewhat for the glycine solution.

The glycine solution had a moderate initial DBPFP of $176 \mu \mathrm{g} \mathrm{L}^{-1}$, and contained all seven of the DBP species (Fig. 5). The DBPFP of the glycine solution did not change significantly 

yield of the organics in the model solution increased from 3 to $51 \mu g \mathrm{mg}^{-1}$ DOC. It appears that the SMPs formed during glycine biodegradation had a much higher DBPFP yield than 
terms of DBP formation reactivity. In other words, although the biodegradation process effectively removes some DBP precursors from wastewater, such as tannic acid and proteins, it may also produce new DBP precursors from carbohydrates and other similar organics with a low initial DBPFP, such as starch and glucose.

Microbial activity played an important role in the transformation of wastewater DBP precursors under simulated natural degradation conditions (Chen et al., 2009; Dotson et al., 2009; Krasner et al., 2009b). The organic transformation results and related DBPFP values in this study differed significantly among the different types of wastewater organic compounds. The DBPFP of humic-like organic matter, which is refractory to biodegradation, was not affected by biological treatment. However, for some of the biodegradable organics with a high DBPFP in wastewater, such as tannic acid and BSA, biodegradation may have destroyed the DBP precursors, thereby greatly reducing the DBPFP of the wastewater. For other biodegradable organics with a low DBPFP, such as glucose and starch, the biological process may have increased both the DBPFP of the wastewater and the DBPFP yield of the organic residues. The final DBPFP of wastewater is probably thus attributable to two sources: the humic-like residue of the organics originally present in the wastewater and the SMPs that are formed during the biodegradation process.

The 10-d biological incubation changed the DBP formation characteristics of the organics in the model solutions and wastewater samples. Initially, the DBPFP yields differed remarkably for different organic DBP precursors. After the biodegradation, owing to the production of SMPs, the DBPFP yields of the organic residues in the four readily biodegradable model organic solutions - glucose, starch, glycine, and BSA - became rather 
comparable. The resulting DBPFP yield values were similar to those of the wastewater influent and effluent organics and somewhat lower than the DBPFP yields of humic 

SMP production during the early stages of dynamic organic degradation contributed to the large DBPFP increase. A similar trend of rapid organic degradation and N-DBPFP increase

\section{Conclusions}


The DBPFP of the raw wastewater influent and secondary effluent samples decreased after the simulated biological organic degradation process, but the remaining organic matter had a higher potential for DBP formation with chlorine. Different model wastewater organics 

be applied to the wastewater effluent or raw water intake for minimization of the wastewater-derived DBP problems in drinking water supply.

\section{Acknowledgements}

This research was supported by grants HKU7149/E06 and HKU7144/E07 from the Keith C. H. Wong is greatly appreciated.

\section{References}

APHA, 1998. Standard Methods for the Examination of Water and Wastewater. $20^{\text {th }}$ ed. American Public Health Association: Washington D.C., USA.

Archer, A.D., Singer, P.C., 2006. Effect of SUVA and enhanced coagulation on removal of TOX precursors. J. Am. Water Works Assoc. 98(8), 97-107.

Arora, H., LeChevallier, M.W., Dixon, K.L., 1997. DBP occurrence survey. J. Am. Water Works Assoc. 89(6), 60-68.

Barker, D.J., Stuckey, D.C., 1999. A review of soluble microbial products (SMP) in wastewater treatment systems. Water Res. 33, 3063-3082.

Bull, R.J., 1993. Toxicity of disinfectants and disinfection byproducts. in: Craun, G.F. (Eds.), Safety of Water Disinfection: Balancing Chemical and Microbial Risks. ILSI Press, Washington D.C., USA, pp. 239-256. 
Chang, E.E., Chiang, P.C., Ko, Y.W., Lan, W.H., 2001. Characteristics of organic precursors and their relationship with disinfection by-products. Chemosphere 44, 1231-1236.

Chen, B.Y., Nam, S.N., Westerhoff, P.K., Krasner, S.W., Amy, G., 2009. Fate of effluent organic matter and DBP precursors in an effluent-dominated river: A case study of wastewater impact on downstream water quality. Water Res. 43, 1755-1765.

Cheng, W.P., Chi, F.H., 2003. Influence of eutrophication on the coagulation efficiency in reservoir water. Chemosphere 53, 773-778.

Chu, H.P., Wong, J.H.C., Li, X.Y., 2002. Trihalomethane formation potentials of organic pollutants in wastewater discharge. Water Sci. Technol. 46(11-12), 401-406.

Dignac, M.F., Ginestet, P., Bruchet, A., Audic, J.M., Derenne, S., Largeau, C., 2001. Changes in the organic composition of wastewater during biological treatment as studied by NMR and IR spectroscopies. Water Sci. Technol. 43(2), 51-58.

Dignac, M.F., Ginestet, P., Rybacki, D., Bruchet, A., Urbain, V., Scribe, P., 2000. Fate of wastewater organic pollution during activated sludge treatment: Nature of residual organic matter. Water Res. 34, 4185-4194.

Domino, M.M., Pepich, B.V., Munch, D.J., Fair, P.S., 2004. Optimizing the determination of haloacetic acids in drinking waters. J. Chromatogr. A 1035, 9-16.

Dotson, A., Westerhoff, P., Krasner, S.W., 2009. Nitrogen enriched dissolved organic matter (DOM) isolates and their affinity to form emerging disinfection by-products. Water Sci. Technol. 60(1), 135-143.

Galapate, R.P., Agustiani, E., Baes, A.U., Ito, K., Okada, M., 1999. Effect of HRT and MLSS on THM precursor removal in the activated sludge process. Water Res. 33, 131-136. 
Galapate, R.P., Kitanaka, A., Ito, K., Mukai, T., Shoto, E., Okada, M., 1997. Origin of trihalomethane (THM) precursors in Kurose River, Hiroshima, Japan. Water Sci. Technol. 35(8), 15-20.

Hua, G.H., Reckhow, D.A., 2007. Characterization of disinfection byproduct precursors based on hydrophobicity and molecular size. Environ. Sci. Technol. 41, 3309-3315.

Hua, G.H., Reckhow, D.A., Kim, J.S., 2006. Effect of bromide and iodide ions on the formation and speciation of disinfection byproducts during chlorination. Environ. Sci. Technol. 40, 3050-3056.

Koivusalo, M., Pukkala, E., Vartiainen, T., Jaakkola, J.J.K., Hakulinen, T., 1997. Drinking water chlorination and cancer - a historical cohort study in Finland. Cancer Cause Control 8, 192-200.

Krasner, S.W., Westerhoff, P., Chen, B.Y., Rittmann, B.E., Amy, G., 2009a. Occurrence of disinfection byproducts in United States wastewater treatment plant effluents. Environ. Sci. Technol. 43, 8320-8325.

Krasner, S.W., Westerhoff, P., Chen, B.Y., Rittmann, B.E., Nam, S.N., Amy, G., 2009b. Impact of wastewater treatment processes on organic carbon, organic nitrogen, and DBP precursors in effluent organic matter. Environ. Sci. Technol. 43, 2911-2918.

Li, X.Y., Chu, H.P., 2003. Membrane bioreactor for the drinking water treatment of polluted surface water supplies. Water Res. 37, 4781- 4791.

Liang, L., Singer, P.C., 2003. Factors influencing the formation and relative distribution of haloacetic acids and trihlomethanes in drinking water. Environ. Sci. Technol. 37, 2920-2928. 
Park, N., Kwon, B., Kim, I.S., 2005. Biofouling potential of various NF membranes with respect to bacteria and their soluble microbial products (SMP): Characterizations, flux decline, and transport parameters. J. Membrane Sci. 258, 43-54.

Reckhow, D.A., Singer, P.C., Malcolm, R.L., 1990. Chlorination of humic materials: Byproduct formation and chemical interpretations. Environ. Sci. Technol. 24, 1655-1664.

Rostad, C.E., Martin, B.S., Barber, L.B., Leenheer, J.A., Daniel, S.R., 2000. Effect of a constructed wetland on disinfection byproducts: Removal processes and production of precursor. Environ. Sci. Technol. 34, 2703-2710.

Singer, P.C., 1999. Formation and Control of Disinfection By-products in Drinking Water. American Water Works Association, Denver, CO, USA.

Sirivedhin, T., Gray, K.A., 2005. Comparison of the disinfection by-product formation potentials between a wastewater effluent and surface waters. Water Res. 39, 1025-1036.

Velp Scientifica. BOD System Operation Manual. Usmate, Italy, http://www.velp.com/en/default.asp.

USEPA, 1995. Methods for The Determination of Organic Compounds in Drinking Water Supplement III, EPA-600/R-95/131, Environmental Monitoring and System Laboratory, United States Environmental Protection Agency, Cincinnati, OH, USA.

USEPA, 2003. Method 552.3: Determination of Haloacetic Acids and Dalapon in Drinking Water by Liquid - Liquid Microextraction, Derivatization and Gas Chromatography with Electron Capture Detection. Environmental Monitoring and System Laboratory, United States Environmental Protection Agency, Cincinnati, OH, USA.

Waller, K., Swan, S.H., DeLorenze, G., Hopkins, B., 1998. Trihalomethanes in drinking water 

and spontaneous abortion. Epidemiology 9, 134-140.

511 Weber, W.J., Huang, Q.G., Pinto, R.A., 2005. Reduction of disinfection byproduct formation matter. Environ. Sci. Technol. 39, 6446-6452.

514 Xie, Y.F., 2004. Disinfection Byproducts in Drinking Water: Formation, Analysis, and Control. CRC Press, Boca Raton, Florida, USA.

Xie, Y.F., Rashid, I., Zhou, H.J., Gammie, L., 2002. Acidic methanol methylation for HAA analysis: Limitations and possible solution. J. Am. Water Works Assoc. 94(11), 115-122. 
Fig. 1. (a) Initial DBPFP yield and (b) mass-based DBPFP speciation of the wastewater and model organic solutions: HA - humic acid, TA - tannic acid, Glu - glucose, 

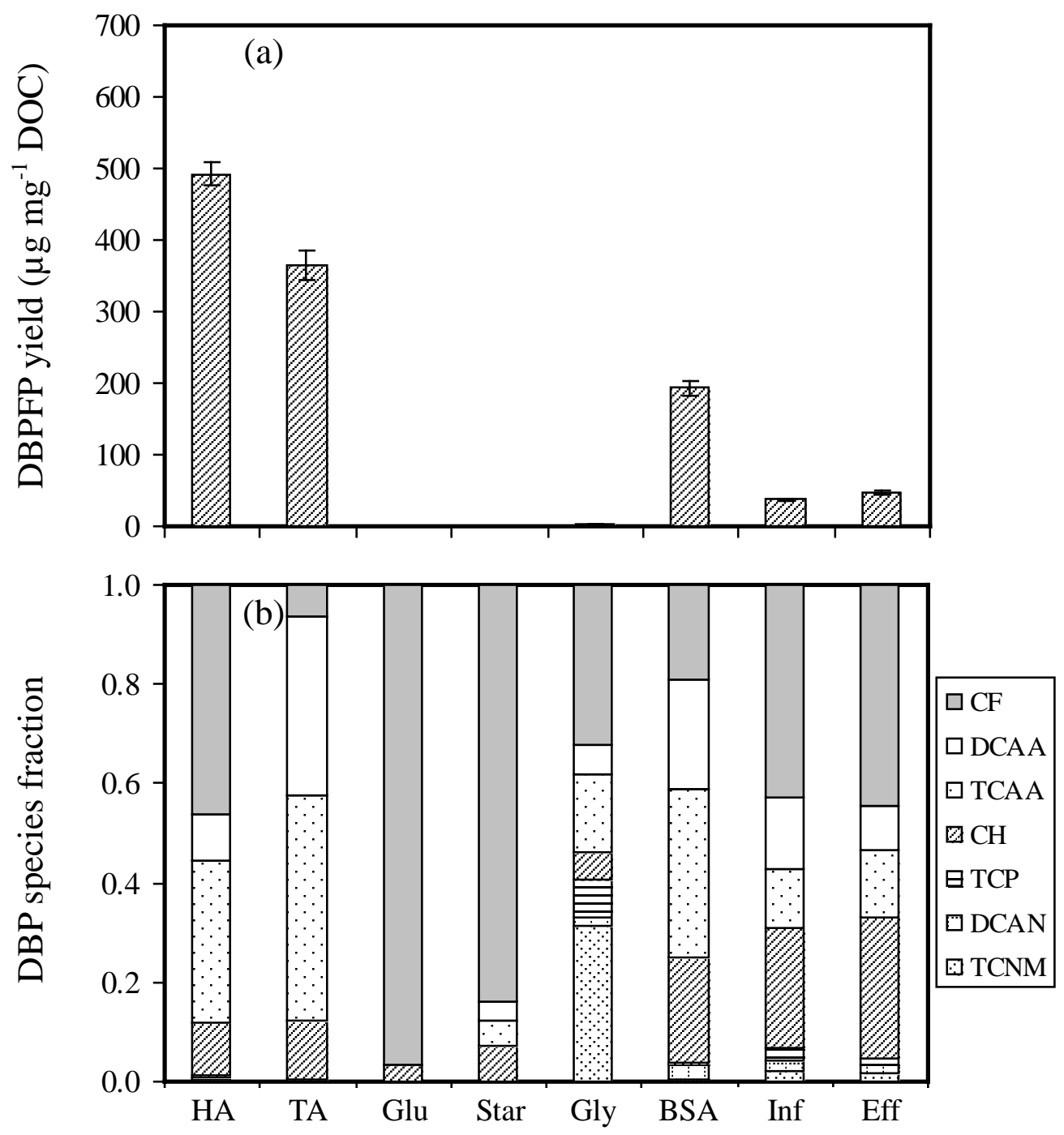

Fig. 1. (a) Initial DBPFP yield and (b) mass-based DBPFP speciation of the wastewater and model organic solutions: HA - humic acid, TA - tannic acid, Glu - glucose, Star starch, Gly - glycine, BSA - bovine serum albumin, Inf - wastewater influent, Eff - secondary wastewater effluent. 

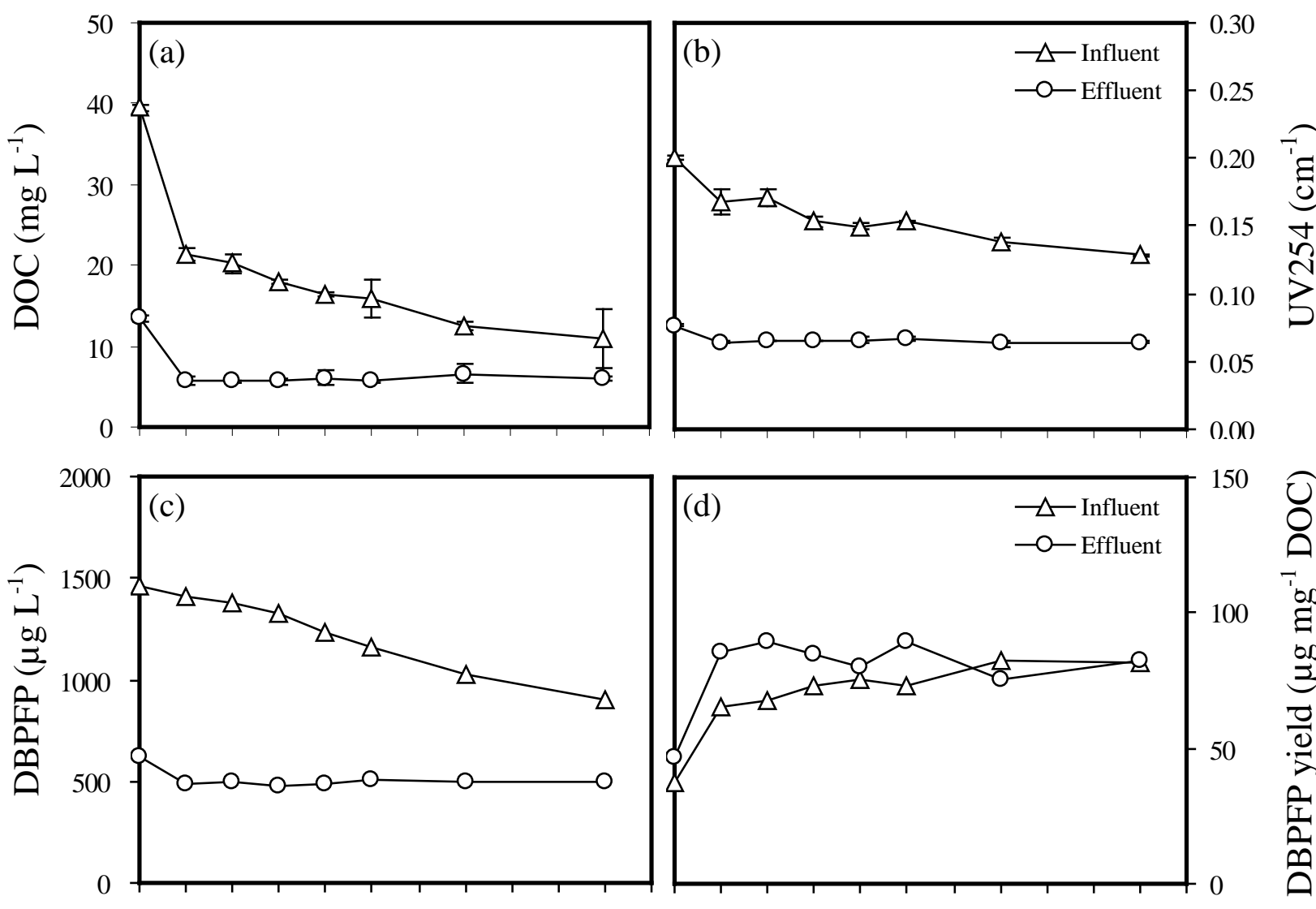

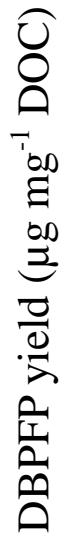

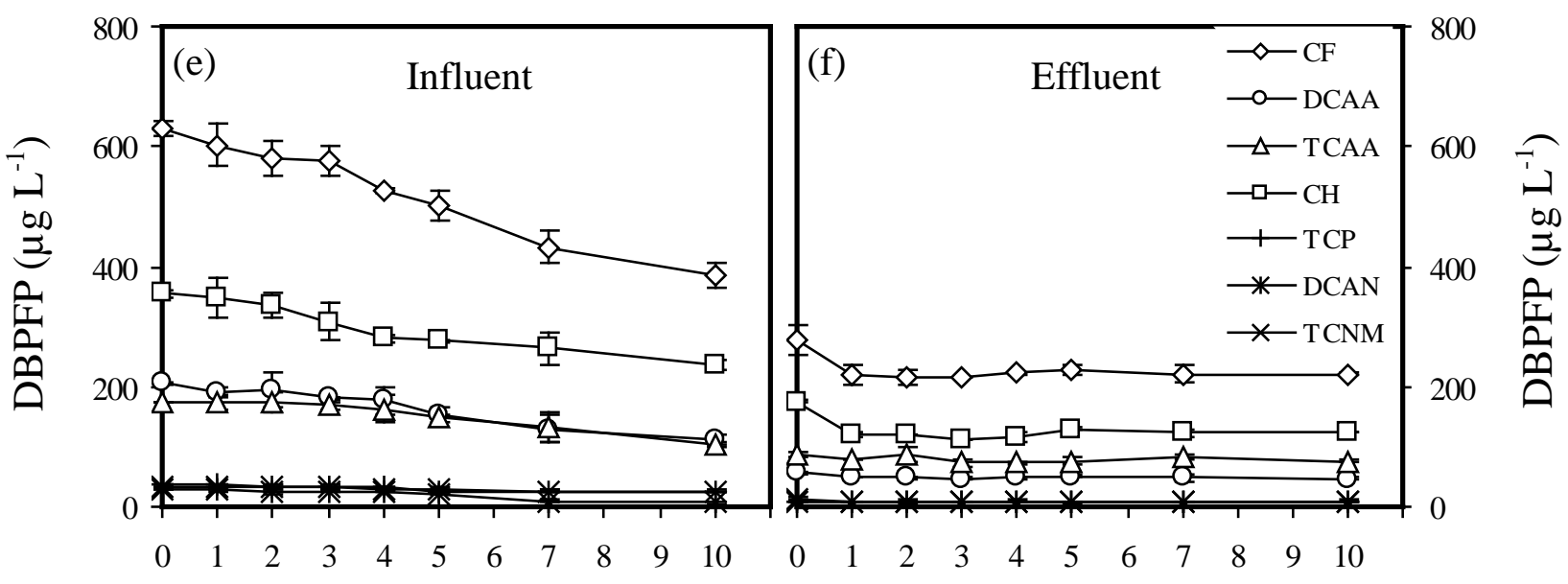

Biodegradation time (d)

Fig. 2. (a) DOC, (b) $\mathrm{UV}_{254}$ absorbance, (c) DBPFP, and (d) DBPFP yield of the wastewater influent and effluent, and DBPFP species in (e) the wastewater influent and (f) the wastewater effluent during biodegradation. 

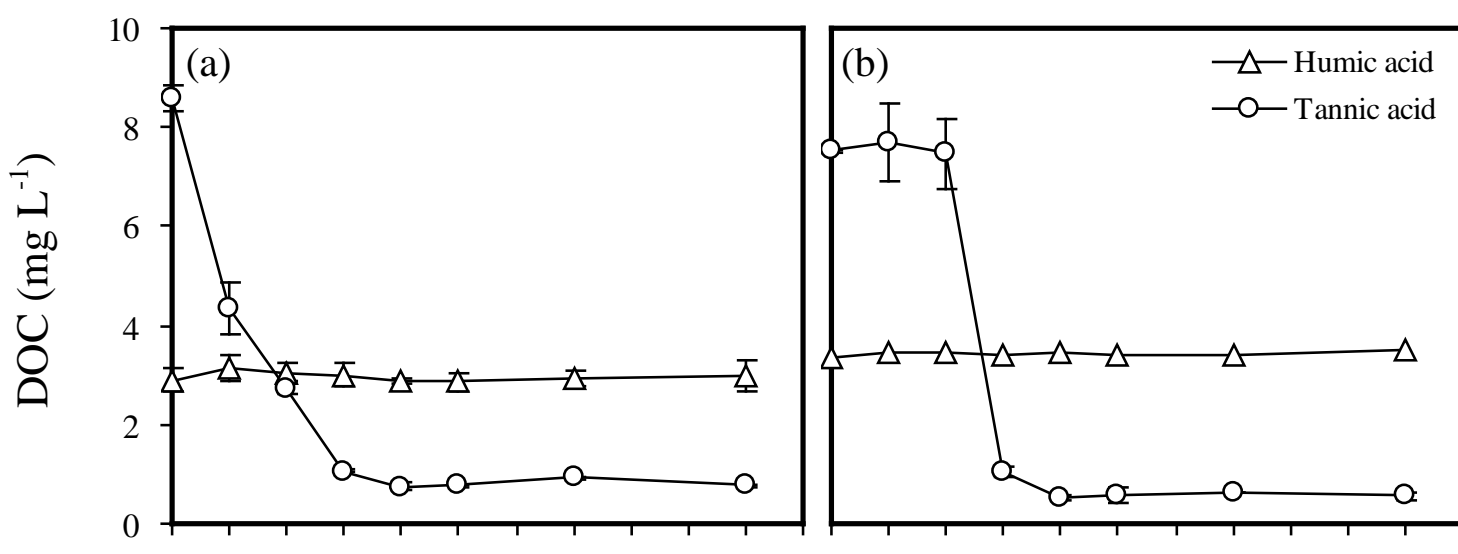

0.60
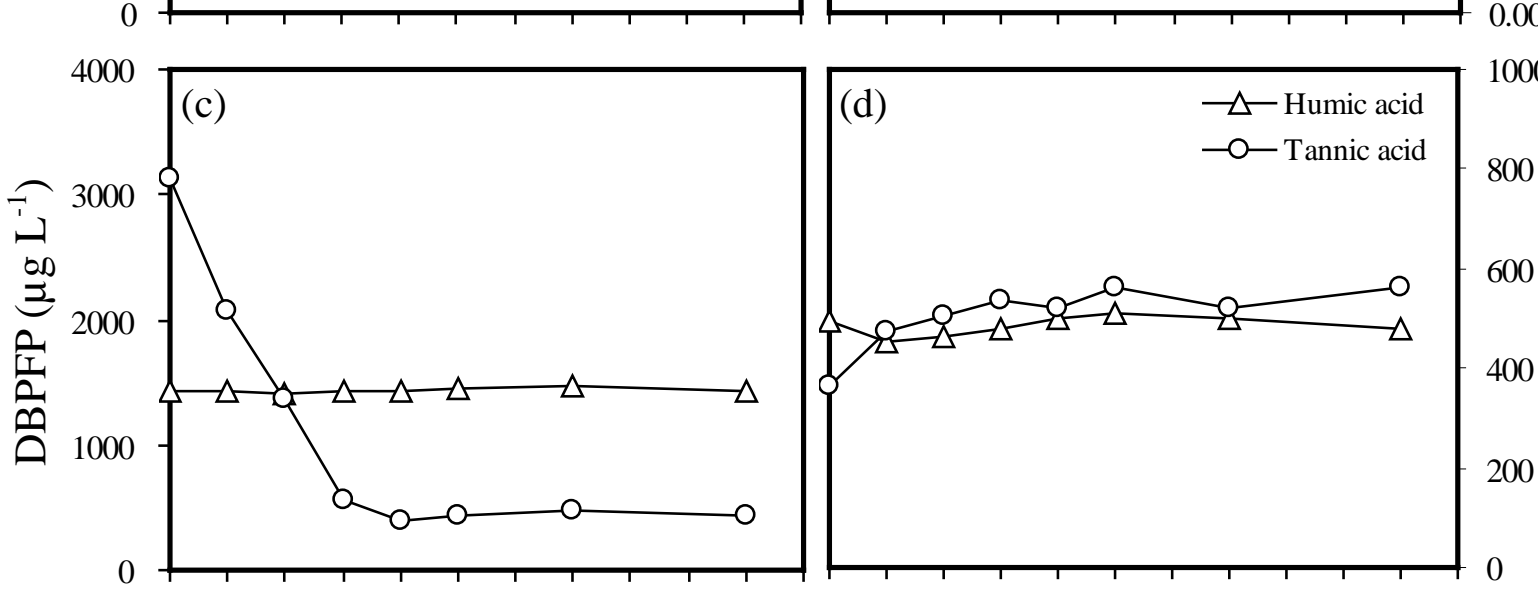

تี
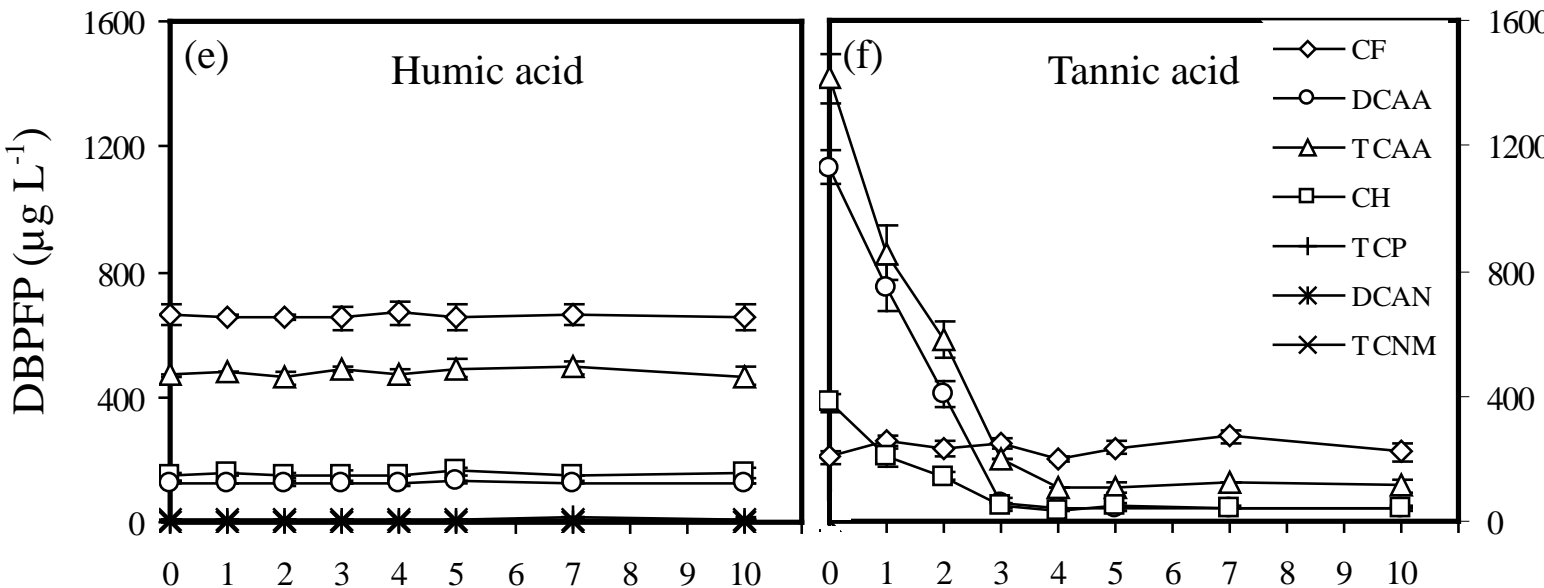

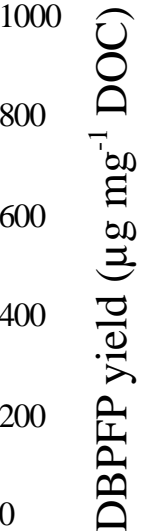

$\begin{array}{llllllllllllllllllll}0 & 1 & 2 & 3 & 4 & 5 & 6 & 7 & 8 & 9 & 10 & 0 & 1 & 2 & 3 & 4 & 5 & 6 & 7 & 8\end{array}$

Biodegradation time (d)

Fig. 3. (a) DOC, (b) $U_{254}$ absorbance, (c) DBPFP, and (d) DBPFP yield of the humic acid and tannic acid solutions, and DBPFP species in (e) the humic acid solution and (f) the tannic acid solution during biodegradation. 


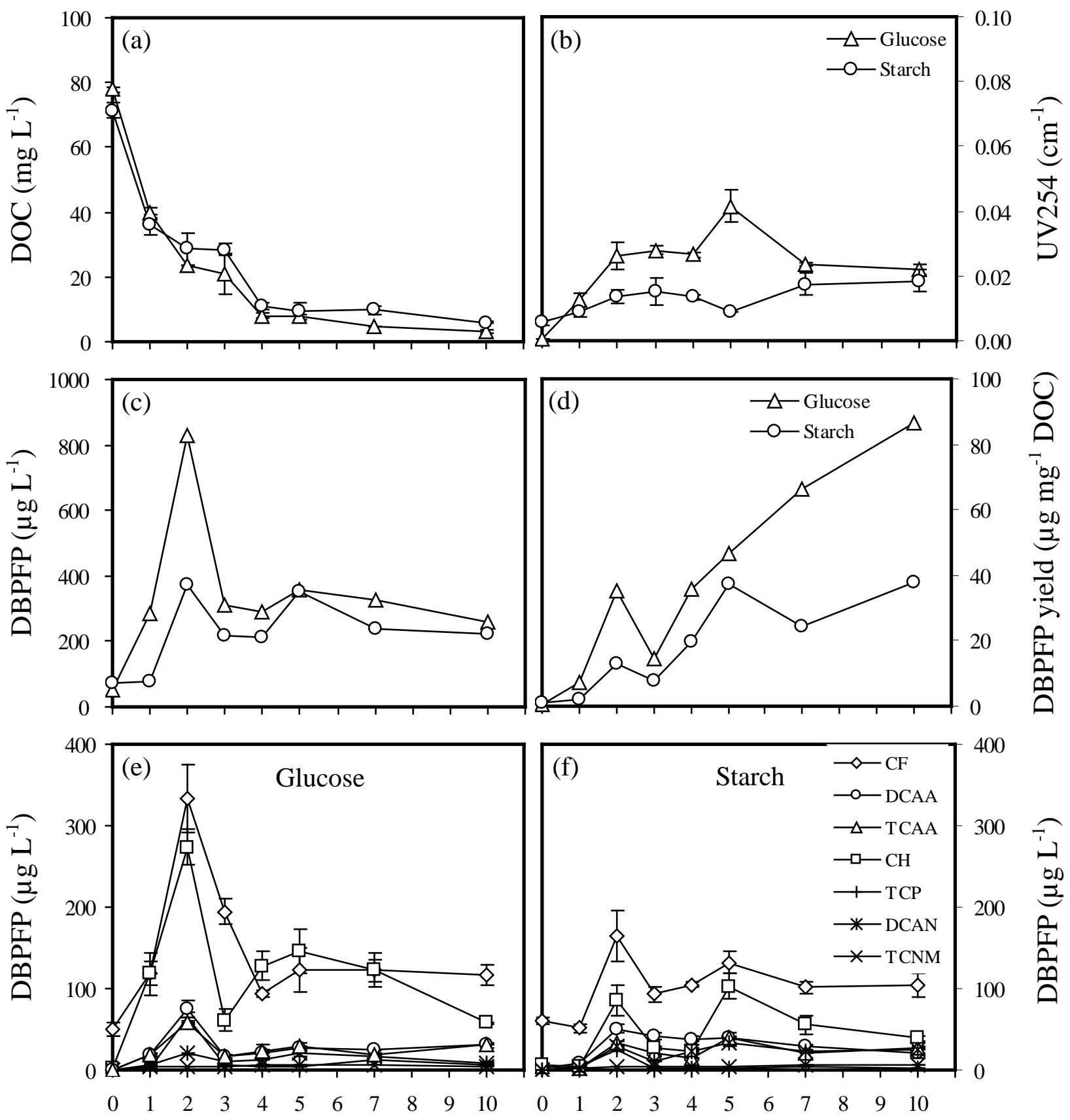

Biodegradation time (d)

Fig. 4. (a) DOC, (b) $U_{254}$ absorbance, (c) DBPFP, and (d) DBPFP yield of the glucose and starch solutions, and DBPFP species in (e) the glucose solution and (f) the starch solution during biodegradation. 

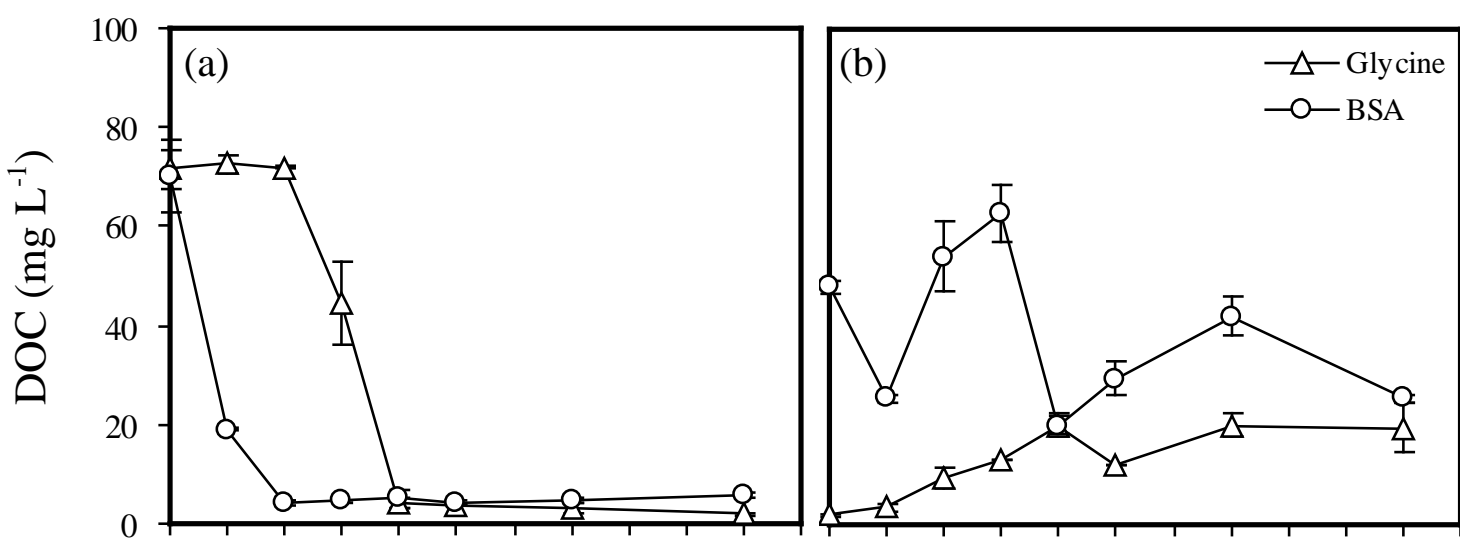

0.10
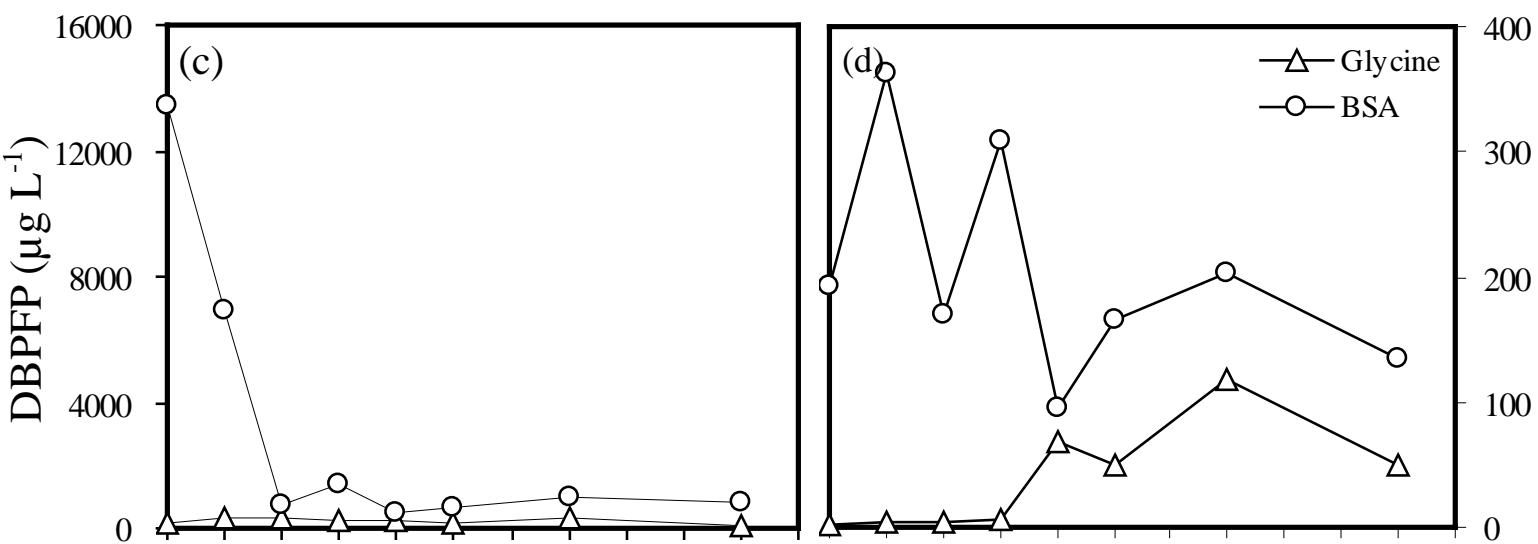

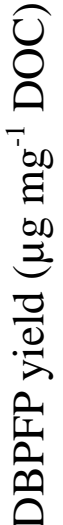
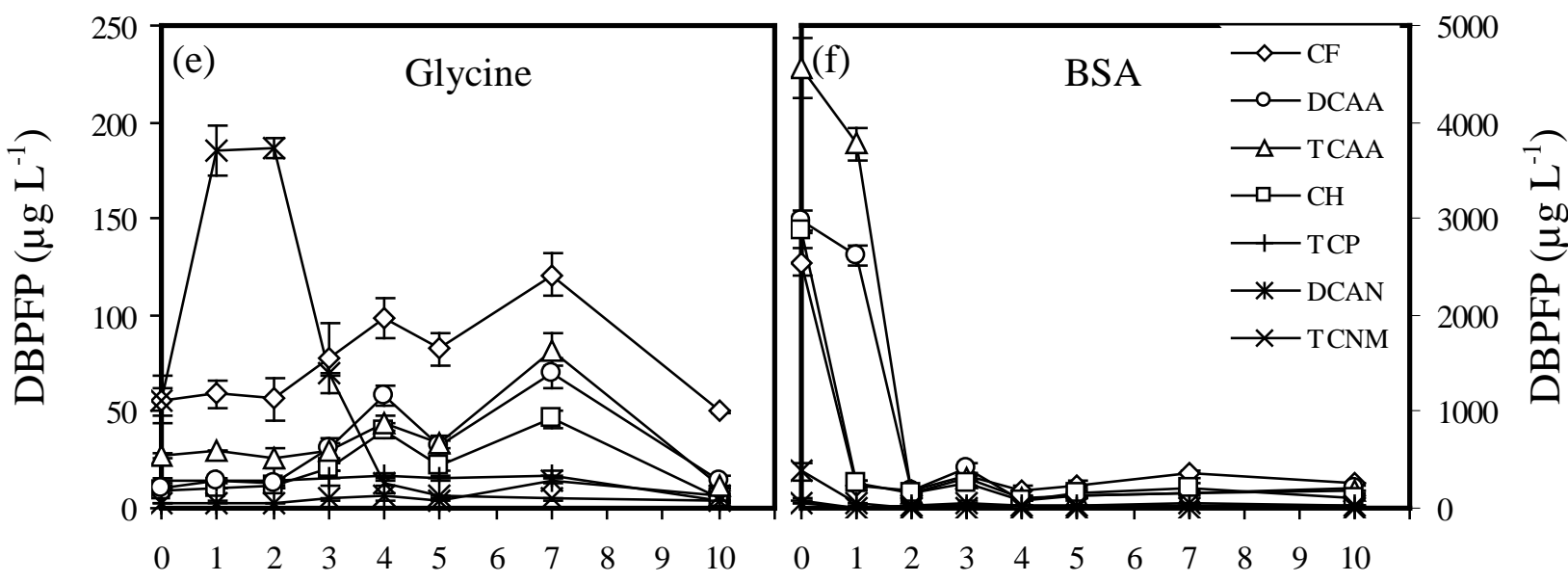

Biodegradation time (d)

Fig. 5. (a) DOC, (b) $U_{254}$ absorbance, (c) DBPFP, and (d) DBPFP yield of the glycine and BSA solutions, and DBPFP species in (e) the glycine solution and (f) the BSA solution during biodegradation. 

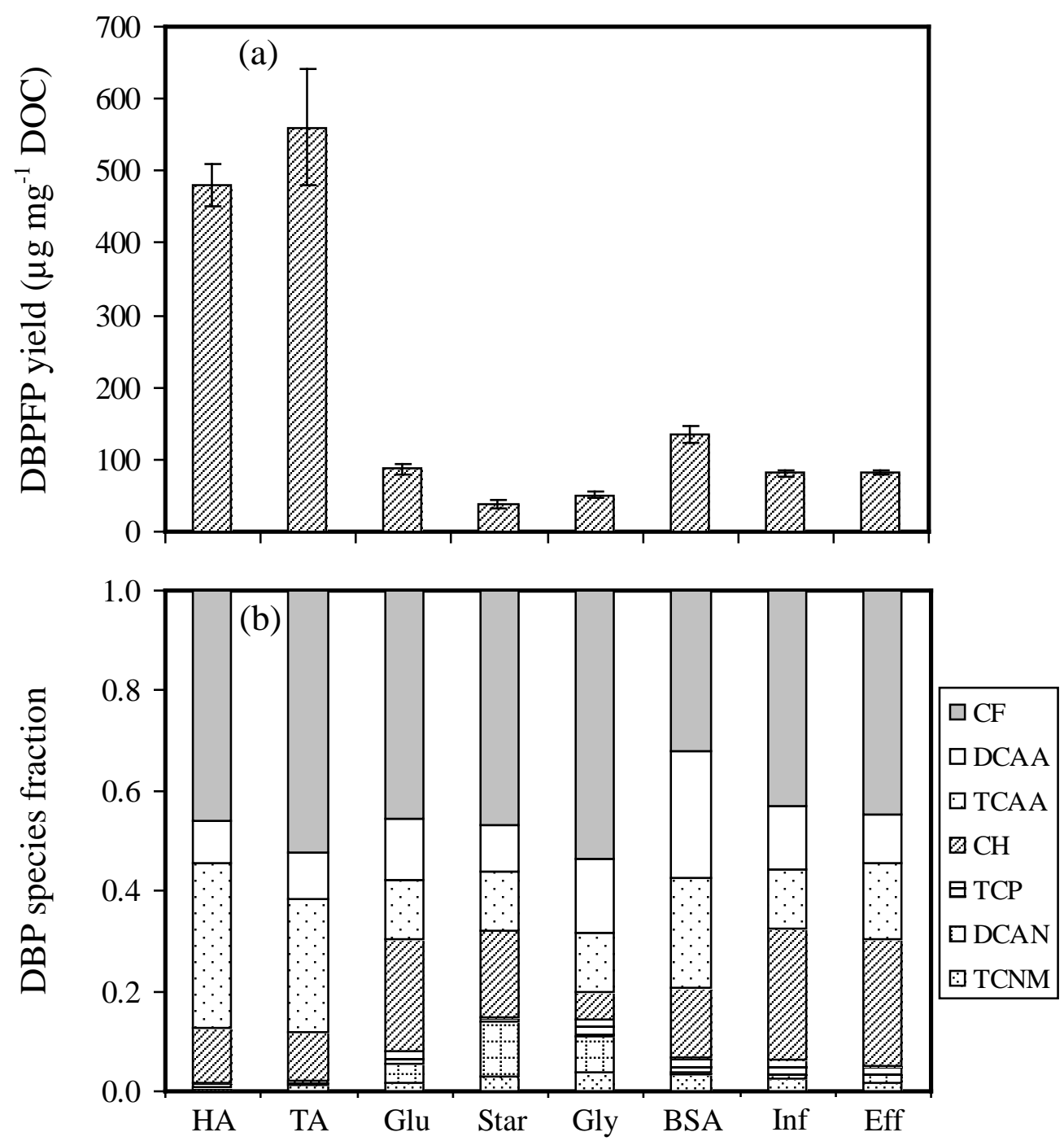

Fig. 6. (a) Final DBPFP yield and (b) mass-based DBPFP speciation of the wastewater and model organic solutions after $10 \mathrm{~d}$ of biodegradation: HA - humic acid, TA - tannic acid, Glu - glucose, Star - starch, Gly - glycine, BSA - bovine serum albumin, Inf - wastewater influent, Eff - secondary wastewater effluent. 

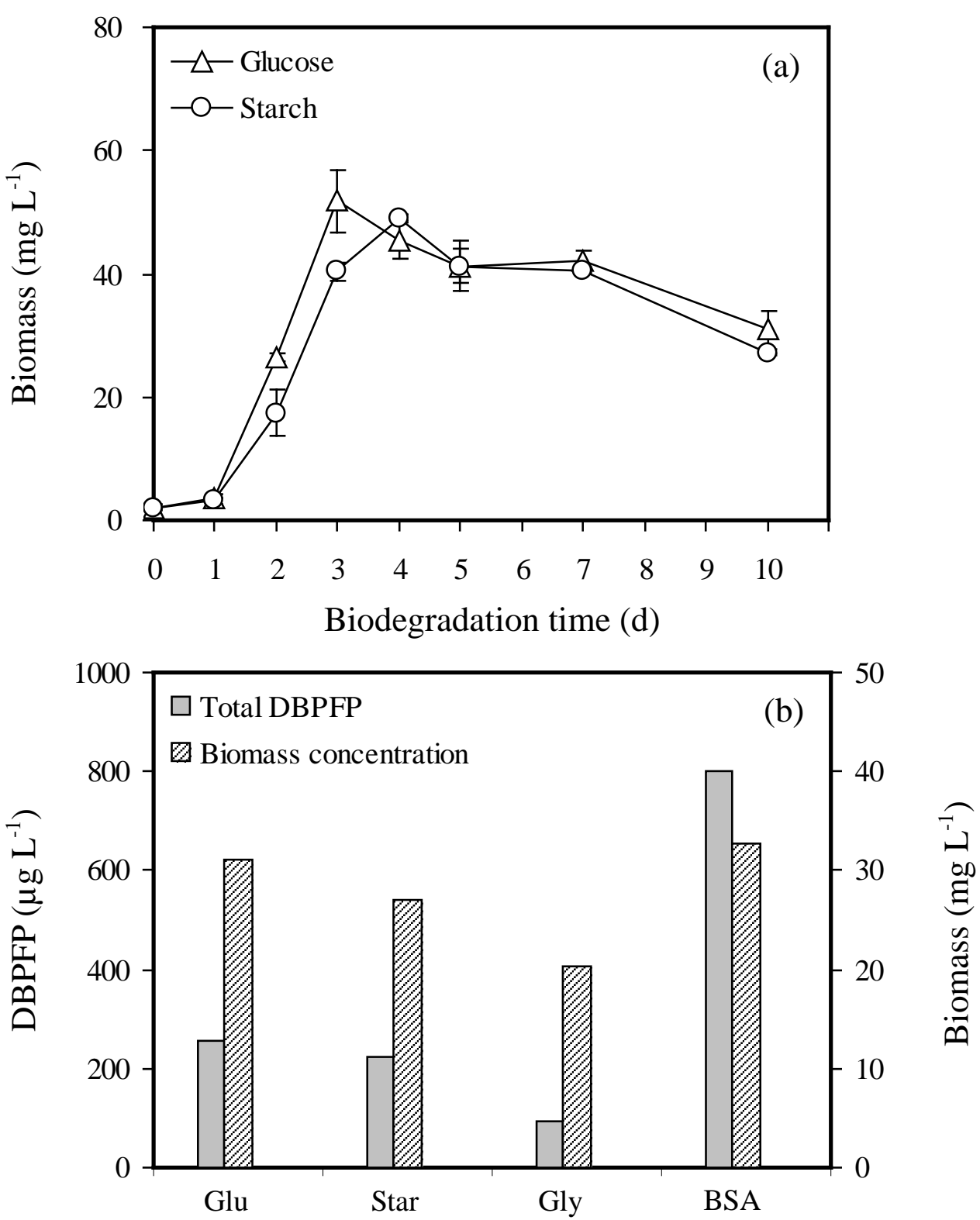

Fig. 7. (a) Biomass concentration during the biodegradation of the glucose and starch solutions, (b) final DBPFP and biomass concentration in the four model organic solutions after biodegradation: Glu - glucose, Star - starch, Gly - glycine, BSA bovine serum albumin. 